\title{
TECHNIQUES FOR PLANNING MICROGRIDS: AN EMPIRICAL STUDY
}

\author{
Kanhaiya Barman \\ M.tech Scholar, \\ Department of Electrical and Electronics \\ Oriental University Indore. India
}

\begin{abstract}
This work discusses the speculative reason behind the procedure snared in to homeostatic control (HC) of electrical power systems, which is anticipated to learn and grasp HES fundamentally the same as living animals that-when worked during a sharp microgrid strategy, grid related and giving ability to an acceptable square - can keep it up as vigilant, open structures inside other higher-demand structures with which they interface and exchange imperativeness. development this speculative structure, huge amounts of coordination and control frameworks for grid tie microgrids is proposed. The technique is anticipated to think about and inside the day's end develop new sorts of economical force source progressions (RETs) for DG of intensity and warmth, working in relating with the system and offering new choices and focal points to imperativeness customers wherever . With the utilization of clever metering and various advances, these canny systems are prepared for talking about and interfacing with various structures so on appear at an adequately balanced essentialness game plan. everything of this is frequently made arrangements for conveying additional focal points to customers and to electric power systems in general inside the present new vision of DG: the customer driven microgrid. Thus, rather than (and enhancing) the rising assessment design in imperativeness the board systems for microgrids, in sight of RETs using demand side organization (DSM) instruments, this paper thinks as an issue of first significance less DSM-which speaks to a major a piece of the investigation design in splendid microgrids (overseeing customer choices and nature of power decisions) starting at now, yet structures response the board. This regarding systems coupling, structures coordination and control, structures shared assistance and each one the significant pieces of their relationship as an elegant adaptable system to deftly control most reasonably and beneficially under a HC plot.
\end{abstract}

Keywords: Power, micro, grid, design

\section{INTRODUCTION}

The standard aims behind this work obey to a strong energy for pushing a chose material to a phenomenal

\author{
Dr Dolly Thankachan \\ Associate Professor and Head \\ Department of Electrical and Electronics \\ Oriental University Indore. India
}

degree unripe right up until this time inside the fields of lattice related microgrids' control, unlimited/elective energies, and legitimate essentialness structures (SES) associated with imperativeness profitability (EE). This concerning imperativeness deftly and usage the board for rural and small size systems where maintainable force sources (RES), and especially non-standard supportable force sources (NCRE) mixed in with customary essentialness sources are joined to the stream power transport establishment. The work needed during this suggestion veers faraway from the conventional approaches to influence the subject went to along these lines by taking a totally unforeseen perspective - a widely inclusive, expansive and essential one, instead of using a lone sided, confined and reductionist system. Thusly it's to highlight to the control of downsized and scaled down scale age power structures from a substitute perspective through and through, using a Systems Thinking (ST) and Cybernetics on account of effect the subject, and that have practical experience in a chose domain alluded to as homeostatic control (HC) of electrical power structures (EPS) which - in all conventionality - has by a strategy or another remained juvenile, beginning time and latent regardless of its exceptional potential and criticalness as showed by Fred C. Schweppe and his gathering of partners very thirty years back. In like manner, during a similarly related system returning to 1991, a fascinating nonstop purchaser control plot for space cooling use under spot power assessing is presented.

So on manufacture progressively viable littler scope age power systems-particularly with respect to creamer economical force source structures (HRES) working joined to the lattice - there is that the got the opportunity to explore new developments and control techniques which will help the progress of passed on age (DG) systems compromise, using the current power establishment during a common sense, capable and moderate way. this is regularly something which falls as per such basic issues as EPS decentralization, splendid system propels, and accordingly the got the chance to have an undeniably versatile, customer arranged, and modified electric power smoothly; especially now that NCRE might be a noteworthy driver round the world. Something that is no vulnerability eagerly joined with EE and customer choice in essentialness use under a 
versatile, customer driven, steady client control plot. Such a system must follow essentialness promote characteristics went to before [9], for example, isolated spot power assessing for instance using contribution as how to fortify imperativeness legitimacy (ES). to chase after the last, the suggestion sets out to review the topics encompassing the subject, investigating the motivation, the advancements and consequently the refore the strategies behind the control of network related HRES and the principles and contemplations behind $\mathrm{HC}$, and a while later continues ahead to look into another vision of managerial control techniques snared in to $\mathrm{HC}$ norms for HRES. It does so arranged to a point on multi-measures dynamic so on move the division of homeostatic control (HC) of EPS, expanding the examination of its applications and possible results into the assessment of plausible essentialness dynamic choices and power effortlessly control procedures in that. are frequently "> this is regularly pointed towards extending the strategies by which DG can be melded to this, exceptionally conventional power age and scattering structure in order to shape the essentialness customers less dependent on oil subsidiaries and other standard techniques for power deftly which are normal of our present imperativeness network in Chile. At the same time there's a necessity to offer progressively handy, monetarily shrewd, versatile and moderate electric power nimbly to buyersparticularly little clients in neighbourhoods with low people thickness where electric power transmission and course organizations are exorbitant and frail.

\section{LITERATURE REVIEW}

Outfitting society with secure and legitimate essentialness and at the same time, doing combating imperativeness desperation sets a genuine test to the imperativeness establishment [1]. The advancement of the imperativeness structure is significant yet the pathway isn't clear, in light of the fact that it isn't only a change inside the essentialness source rather it describes the area, national and overall authoritative issues for very while [2]. Decentralized imperativeness systems increment this modification by organizing maintainable force source into the structure as microgrid, essentialness storing system, littler scope cogeneration, at that point on [2]. The decentralized imperativeness structures are extending with growing prosumer, essentialness systems, and Peerto-Peer imperativeness trading [2]. the occasion of decentralized systems are regularly credited to less expensive sun fueled cells and profitable mechanical assemblies [2]. With decentralized essentialness structures discovered, the client is playing a working activity. Customer's activity inside the essentialness structure has created from fundamentally an endcustomer to an even more exceptional substance to shape a system as microgrids and P2P imperativeness trading. In any case, the buyers work is so far not emphasizd all together that rolls out evident improvement inside the imperativeness structure which has been stressed by [3] demonstrating that purchasers not only are customers; they're also producers and legitimators who can coordinate a change independently even as taking everything into account. A legitimator is one who changes the will for individuals by astute and unequivocally giving significance, reason, and strategy for thinking for their activities.

Moreover, the nearness of splendid cross sections inside the decentralized structures can change the surrounding political course of action, publicize on-screen characters at the same time [3], as opposed to the normal flow system. Be that since it might, how it'll change or the framework for change isn't huge amounts of clear. during along these lines, Levenda [4] proposed the requirement for additional assessment inside the sociotechnical change of the essentialness system to the extent power and organization. Moreover, understanding the different buyers and their motivations are suggested in, [4]. Purchasers have for since very while prior been considered as unapproachable end-customer of imperativeness inside the traditional system [5]. The progress in supportable force source propels, for instance , sun arranged cells has changed clients into creators and with sharp system progresses, customers took an enthusiasm inside the intrigue side organization programs. The coordination of information and correspondence advancement [5] has brought the buyers one step ahead as agents inside the market.

As the sharp cross section is another development, the fundamental assessments on the client have explored the affirmation of the advancement because of the current weakness in regards to controllability, data assurance, prosperity danger, cash related concerns, at that point forward. [6]. From that time forward, the more noteworthy a piece of the splendid network inspects that included purchasers has focusing on demand side organization using differing time touchy assessing and persuading powers based frameworks [7]. the reason for this investigation was for the principal part to get the reasonability of client's lead change inside the splendid grid system. Various assessments have asserted the accomplishment of buyer intrigue at the same time and along these lines the ability to move demand, reducing essentialness usage [7]. Regardless of the very reality that the direct change wasn't only the result of different helpers to require an intrigue rather a computerization of devices [8], information communicating [8], analysis [9] expected a difficult task among various parts.

An equivalent course of action of research that is appropriate for $\mathrm{P} 2 \mathrm{P}$ essentialness trading is prosumers. Gradually buyer asks about focusing on prosumer and prosumer systems [26]. System imperativeness which might be an acclaimed wonder far and wide are regularly seen as how to empower clients $[10,11]$. The diminished 
cost in microgrid advancement joined with a creating trading stage with the assistance of ICT is realizing an extension of this sort of essentialness organize [10,11]. The creative movement has made online stages which have encouraged mutual trading the office part as well $[10,11]$. By and by people produce their imperativeness additionally as trade it with their buddies $[10,11]$.

Examiners have arranged crafted by purchasers from only a taking an intrigue substance inside the intrigue response program to an even more great trading component as prosumers. Regardless, the customer's activity as DR individuals, prosumer, imperativeness arrange, $\mathrm{P} 2 \mathrm{P}$ trader all are solidly related, for example, the main part of the $\mathrm{P} 2 \mathrm{P}$ adventures have some prosumers, a portion of the $\mathrm{P} 2 \mathrm{P}$ adventures have microgrid systems. This paper will consider P2P essentialness trading a microgrid structure.

Prosumers: Prosumers are customers who can make, eat up, store and sell their imperativeness [12]. the idea of prosumer got archived to enter high volume of supportable force source into the essentialness mix. Prosumers with sharp systems are probably going to help improve the imperativeness capability inside the structure once they are roused through various money related, operational and biological focal points [13].

Essentialness social order: Energy society are those gettogethers of individuals who will for the most part either make or extra imperativeness or do both [14].

As showed by article 16, an occupants essentialness system might be a social occasion of individuals who can lease, guarantee or discovered system sort out and may self-ruling administer them, hold a decision to take an enthusiasm inside the business areas, should be guaranteed as a client with non-discriminatory power obligation, at that point subsequently is in like manner referenced inside the proposed order that part states will ensure fitting rule to guarantee purposeful venture of customers in such systems and that they save the decision to leave the system. A captivating point to see here is that there's no geographical breaking point or number described for the occasion of a system.

Circulated trading is the place companions or neighborhood systems trade imperativeness without the intervention of any standard essentialness feature performer with the assistance of ICT [15]. P2P imperativeness trading can happen between two houses or in two structures on an amassed level dependent upon its arrangement.

The current examination will consider the P2P essentialness trading a system microgrid and what motivations work behind such structures from two microgrids. The going with zone will explain the system microgrid and thusly the activity of $\mathrm{P} 2 \mathrm{P}$ shippers. Dispersed trading [16], has as of late been archived with sharing things and organizations among the buyers honestly, bypassing the standard arbiter on-screen characters [17]. This has changed the client server approach by making the structure progressively gainful that was unreasonable with the standard business to customer publicize. The surge of $\mathrm{P} 2 \mathrm{P}$ trading has enabled diverse establishment of coordinated effort for the client and it's spread to the imperativeness zone likewise [18]. There are various $\mathrm{P} 2 \mathrm{P}$ essentialness trading adventures with undeniable features some consideration on the game plan and stage for grandstand game plan for trading as done by Piclo and Vandebron adventure inside the UK and in this way the Netherlands. Others center around the development and ICT answers for microgrid and neighborhood control establishment for instance Community first! town in Texas, USA. Be that since it might, the $\mathrm{P} 2 \mathrm{P}$ trading adventures have disregarded the possibility of the local essentialness grandstand inside the microgrid [19].

P2P imperativeness trading might be a stunning trade process that has several layers. inside the primary spot, there's trading between peers, second an effect instrument exists for taking care of the trading system that fills in as a phase ultimately, there's a physical transmission of the office through power cross section [20]. A similar layering has been referenced in a few examinations trading as a business layer, the motivation of trading as an effect layer, information stream as ICT layer ultimately the physical force trading between peers as power arrange layer [21]. [21] have combined the information and along these lines the control layer as an information arrange. to highlight to its multifaceted nature, P2P essentialness trading can occur in a few levels, for instance , a) trading inside microgrid , b) trading inside a CELL [22] and c) trading among CELLs inside seeing a market [26]. Practically identical levels are recognized by Pouttu et al., [26] during a P2P trading structure, for example , microgrid to microgrid, microgrid to prosumer and microgrid to aggregators. Here, the aggregator is seen as another on-screen character inside the market who will be responsible for regulating or modifying the loads [23] inside the lattices for little and medium-sized prosumer and purchasers [23]. An aggregator are frequently another performer outside of the current imperativeness structure or it okay could likewise be someone inside the system.

Buyer's activity as a working on-screen character inside the force system is because of the mix of economical force sources into the family members levels and along these lines the intrigue side organization using the wise meters. during thusly, prosumers and $\mathrm{P} 2 \mathrm{P}$ traders and versatility provider inside the system is immovably related during a splendid system structure. 
Nearby the arrangement of $\mathrm{P} 2 \mathrm{P}$ structure, the money related model for trading is furthermore a major consider the $\mathrm{P} 2 \mathrm{P}$ essentialness trading system. Here, the money related model techniques the segment used for trading the essentialness between peers the recently referenced sorts of systems. Inside a microgrid system separating the bills among the companion in the wake of trading; using the conventional expense of essentialness for trading; empty based esteeming at a given time, at that point forward are a portion of the procedures referenced by [24]. however, , a rigid expense for fulfilling the intrigue snared in to genuine data and an exceptional expense for each and each offering are two methods for money related exhibiting suggested by [24].

The P2P imperativeness trading has showed up as deal based assessing and in this way the nearness of blockchain development and splendid system propels have made it less complex for companions to trade as found inside the Vandebron, Brooklyn Microgrid [25]. The fundamental $\mathrm{P} 2 \mathrm{P}$ adventures anticipated testing diverse specific wellness of the methodology. the utilization of maintainable force sources inside the system was one among the numerous goals. Piclo, Vandebron these two endeavors began P2P trading from a supplier's perspective where buyers can pick their supplier. SonnenCommunity might be an errand in Germany that introduced $\mathrm{P} 2 \mathrm{P}$ trading from a limit perspective where the buyers share their set aside imperativeness. aside from this, the requirement for a web advertise stage has encouraged endeavors to check cloud-based stages, for example, in PeerEnergyCloud adventure. The extension of blockchain has given the $\mathrm{P} 2 \mathrm{P}$ essentialness trading an inexorably solid system. Assignments like Energy Collective in Denmark and EMPOWER have focused more on the imperativeness system completely thinking about the purchasers from an extensive perspective. The Energy Collective errand concentrated on a region imperativeness grandstand association and EMPOWER made arrangements for fusing the prosumers into the market. Execution of clever lattice structure is to some degree moderate diverged from how this word has made the advancement. The suggested blocks as perceived by Muench, Thuss, and Guenther, [26] consolidates cost and points of interest, data and institutional instrument. The end-customers don't think about the open entryways inside the market and besides the peril of information security hampers the take-up of insightful structure advancements. For the end-customers, the preventions are frequently overpowered by applying huge amounts of pathways, for example, exhorting the customers, making regard included focal points inside the market and acclimating to new changes. this may prepare oneself against a change inside the imperativeness region.

An assessment inside the Netherlands has ordered the imperativeness become two or three districts, for example, an advancement of source, use, social, agrarian, charge and microeconomic trade progress [26]. Among these regions, source and usage progresses are genuinely related to the essentialness grandstand. Source progress insinuates the change from fossil to maintainable sources however the utilization change implies fluctuate in other usage needs from oil subsidiary to endless, for example, warming to be done with destroy. the remainder of the change zones are the consequences of direct advancement. a portion of the outcomes of the prompt changes are moving of obligation from renewables to propel its turn of events, counterbalancing the agrarian land with the space required for supportable force source age, reduced dependence on non-sustainable power source based organizations for work with an open door for little extension trading. The social impacts are the care among people about the essentialness structure and continuously neighborhood imperativeness organizations.

From a client fortifying perspective changes are anticipated in, [26] considering the examples for the more drawn out term, for example, extending usage of boundless sources, mutt courses of action, progressively savvy grid game plans with open and participatory imperativeness grandstand, scattered and close by essentialness, demand response, headway for by and large practicality and occupation of imperativeness as a chance and organization. those examples of future imperativeness region have impacts on drawing in purchasers through being continuously taught on the helpful courses of action snared in to feasible force source, dynamic enthusiasm inside the market with selling essentialness, making customer arranged game plans, occupants as information provider needed response, strengthening crafted by neighborhood associations in organizing, circled creation freeing the route from little creators.

\section{CONCLUSION}

The essentialness region is encountering a change from oil-based goods to limitless sources because of the decarbonizing economy through manageable force source joining; extended enthusiasm for power use inside the vehicle and mechanical part. The advancement is as per the IPCC report, which includes dynamically snappy action to fight ecological change, underlining the requirement for taking care of the intrigue side of imperativeness especially inside the force zone. the trouble becomes gigantic when the estimation of individuals living in urban zones by 2050 is around $70 \%$. The high urbanization rate and extending imperativeness demand gather that the current network establishment most likely won't be discovered to help the people while manufacturing new structure needs time and theory. during this condition adroit grid and microgrids can accept a challenging task by joining practical force source, ensuring steadfast quality, and engaging solicitation side organization. 
To support this advancement, the EU rule underlines dynamic client's venture inside the imperativeness structure. one among the duties of the microgrid is its independence from the course system and sharing inside clients. This offers rise to an alternate turn of events - the Peer-to-Peer trading system. it's a totally special gratitude to influence an imperativeness system where people can share and trade essentialness between themselves with the proximity of a trading stage. the idea of $\mathrm{P} 2 \mathrm{P}$ essentialness trading has occur because of a decentralized imperativeness system that shows the need to incorporate maintainable force source and imperativeness independence. The creating thought of the network economy seems to have pushed prosumers to give their imperativeness and trade to each other. an outsized part of the asks about on $\mathrm{P} 2 \mathrm{P}$ imperativeness trading is so far happening inside the particular space, not particularly is accepted about the money related dynamic of this novel system. it's fundamental to comprehend the money related charge related to the expansion of this kind of inventive imperativeness structure because of sharp systems.

Sweden has enthusiastic concentrations to be $100 \%$ feasible force source driven by 2040. Regardless, bits of Sweden are encountering system blockage that stops differing new enhancements during a couple of urban networks. These show a strong got the opportunity to find courses of action that are gainful and incredible to manage the trouble of structure stop up. since the P2P imperativeness trading microgrid can to some degree post of the essentialness issues, the current assessment examined its potential in Swedish microgrids.

\section{REFERENCES}

[1] A. M. Adil, and Y. Ko, (2016). Socio-particular improvement of Decentralized Energy Systems: An essential overview and recommendations for urban organizing and approach. Unlimited and Sustainable Energy Reviews, 57, 1025-1037. https://doi.org/10.1016/j.rser.2015.12.079

[2] K. O Adu-kankam,., and L. M. Camarinha-matos, (2019). Rising Community Energy Ecosystems : Analysis of Organizational and Governance Structures of Selected Representative Cases. tenth IFIP WG 5.5/SOCOLNET Advanced Doctoral Conference on Computing, Electrical and Industrial Systems, DoCEIS 2019 - Technological Innovation for Industrial and fix Systems, 553, 25-40. https://doi.org/10.1007/978-3-030-17771-3

[3] , A. T. Al-Awami, and E. Sortomme, (2012). Arranging vehicle-to-cross section organizations with essentialness trading. IEEE Transactions on Smart Grid, $3(1)$, 453-462.
[4] A Alabdulkarim,. Z. Lukszo, ; and T. W. Fens, (2012). Affirmation of Privacy-Sensitive Infrastructure Systems: A Case of Smart Metering inside the Netherlands, 18-20.

[5] P. Alstone, , D. Gershenson, , and D. M. Kammen, (2015). Decentralized imperativeness systems for clean force get to. Nature worldwide environmental change , 5(4), 305-314. https://doi.org/10.1038/nclimate2512

[6] S. Bager, , and L. Mundaca, (2017). Making 'Sharp Meters' increasingly shrewd? Encounters from a lead money related issues pilot field break down in Copenhagen, Denmark. Imperativeness Research and science 28(April), 68-76. https://doi.org/10.1016/j.erss.2017.04.008

[7] C. Bartusch, , F. Wallin, , M. Odlare, , I. Vassileva, and L. Wester, (2011). Introducing an intrigue based force dispersal obligation inside the private zone: Demand response and customer insight. Imperativeness Policy, 39(9), 5008-5025. https://doi.org/10.1016/j.enpol.2011.06.013

[8] A. Beaulieu, (2017). A. Beaulieu, J. de Wilde, and J. M. . Scherpen (Eds.), Smart Grids from an overall Perspective. Recuperated from https://www.springer.com/gp/book/9783319280752

[9] R. Bray, , and B. Woodman, (2019). Obstacles to Independent Aggregators in Europe. EPG Working Paper: EPG 1901, 1-41.

[10] A. E Broughel,., A. Stauch, , B. Schmid, , and P. Vuichard, (2019). Essentialness Transition Financing Consumer Co-Ownership in Renewables. In J. Lowitzsch (Ed.). Springer Nature Switzerland AG. https://doi.org/10.1007/978-3-319-93518-8

[11] M. Brolin, (2017). Aggregator trading and solicitation dispatch under expense and weight weakness. IEEE PES Innovative Smart Grid Technologies Conference Europe, 1-6. https://doi.org/10.1109/ISGTEurope.2016.7856228

[12] M. J. Burke, , and J. C. Stephens, (2018). Political power and reasonable force source destinies: An essential review. Imperativeness Research and science, 35(October 2017), 78-93. https://doi.org/10.1016/j.erss.2017.10.018

[13] M. C Buth,. A. J. Wieczorek,. (2019). The potential impact of blockchain on the on-screen character course of action inside the Dutch force system. Essentialness Research and science, pp 194-205. https://doi.org/10.1016/j.erss.2019.02.021 
[14] M. C. J. Caniëls, , and H. A. Romijn, (2008). Onscreen character masterminds in Strategic Niche Management: Insights from casual association speculation. Possibilities, 40(7), 613-629. https://doi.org/10.1016/j.futures.2007.12.005

[15] CEER. (2019). Regulatory Aspects of SelfConsumption and Energy Communities CEER Report.

[16] J. Clark, (2016). what's the snare of Things, and the way would it be able to work? Recuperated August 30, 2019, from https://www.ibm.com/online diaries/web ofthings/what-is-the-iot/

[17] M. Cupelli, (2017). Assessment and relationship of EU-wide rules and rules concerning the commercialization of end-customers flexibility and building close by imperativeness business focuses/stages V1.0. Recuperated from https://interflex-h2020.com/wpcontent/moves/2018/06/D8.9-EU-wide-rules and-rulesconcerning-building-close by essentialness business focus platform.pdf

[18] , S. J. Darby (2012). Metering: EU course of action and recommendations for fuel poor nuclear families. Imperativeness Policy, 49, 98-106. https://doi.org/10.1016/j.enpol.2011.11.065

[19] H. Dick, , H. Eden, , G. Fischer, , and J. Zietz, (2012). Empowering customers to become makers, (November 2014), 49. https://doi.org/10.1145/2348144.2348160

[20] L. Diestelmeier, (2019). Advancing force: Shifting crafted by power customers with blockchain development - Policy proposals for EU Stevens' law . Imperativeness Policy, 128(December 2018), 189-196. https://doi.org/10.1016/j.enpol.2018.12.065

$\mathrm{u} /$
[21] E. Dütschke, , and A. G. Paetz, (2013). Dynamic force assessing Which undertakings do customers like? Essentialness Policy, 59, 226-234. https://doi.org/10.1016/j.enpol.2013.03.025

[22] E.On. (2018). Yearly Report 2018. recuperated from https://www.eon.com/content/dam/age/age com/budgetary masters/financial specialists meeting/2019/Annual_Report_2018.pdf

[23] A.Eriksmö, , L. Hernandez, , A. Krüger, , H. Balar, , T. Fischer, , and P. Zanden-Kjellen, (2017). D8.1 and D8.2: Detailed Use Case Planning ID and Title : D8.1 Detailed Use Case Planning Revision and extra Input E.ON Internal review (settlement to INTERFLEX inside overview). Recuperated from https://interflexh2020.com/wp-content/moves/2018/07/D8.1-E.ON-

Sweden-DEMO-Detailed-use-case-masterminding .pdf

[24] E.Espe, , V.Potdar, , and E. Chang, (2018). Prosumer Communities and Relationships in Smart Grids: A Literature Review, Evolution and Future Directions. Energies, 11(10), 2528. https://doi.org/10.3390/en11102528

[25] P.Fenton, , S. Gustafsson, J. Ivner, , and J. Palm, (2015). Doable essentialness and air frameworks: Lessons from masterminding structures in five regions. Journal of Cleaner Production, 98, 213-221. https://doi.org/10.1016/j.jclepro.2014.08.001

[26] D. Frieden, , A. Tuerk, , J Roberts,.., S D' Hebermont,.., and A. Gubina, (2019). Total self-use and essentialness systems: Overview of creating managerial approachs in Europe, (June). Recuperated from https://www.compile-project. 